\title{
The evolution of evolutionary molecular medicine
}

\author{
Genomics are transforming evolutionary biology into a science with new importance \\ for modern medicine
}

\author{
Detlev Ganten • Randolph Nesse
}

Published online: 28 April 2012

(C) Springer-Verlag 2012

New technologies have always been the driving forces for major developments in science. Medicine is no exception. New sequencing technologies have enabled us to begin understanding the genomic and molecular origins of life and the reasons for disease; they are also transforming evolutionary biology into a new, precise, molecular science that has enormous promise for advancing medicine and public health [1]. This issue of the Journal of Molecular Medicine has invited papers to discuss this exciting development.

\section{Evolution comes to medicine, genomics comes to evolution}

Medical doctors are trained to taking a detailed history from their patients, their personal history, a family history (and tree if indicated), and the time course symptoms and laboratory tests. Now we look back into the history of mankind and to the origins of life 3.5 billion years ago to understand why we get sick. The history-taking process has thus been extended from the individual to his phylogenetic ancestors.

The transformation of medicine by genomics will eventually be recognized among the most significant in a long history of innovations. The beginnings of modern medicine were made

D. Ganten $(\bowtie)$

Charite-Universitätsmedizin Berlin,

Max Delbrück Centrum für Molekulare Medizin (MDC),

Berlin-Buch, Germany

e-mail: jmmeic@mdc-berlin.de

R. Nesse

The University of Michigan,

3018 East Hall,

Ann Arbor, MI 48109, USA

e-mail: nesse@umich.edu by the ancient Greeks, especially Hippocrates and later Galen. Their free and unbiased observations, descriptions, and interpretations of natural phenomena invented modern science and allowed applying science to medicine. Their ideas were revived in the Renaissance, when Leonardo da Vinci, Michelangelo, and Vesalius introduced functional analysis and scientific anatomy of the human body. William Harvey in England, Claude Bernard in Paris, and Johannes Peter Müller in Berlin supplanted the ideas of Galen and Hippocrates. The ingenious scientific experiments of these investigators led to a remarkably improved understanding of human physiology and pathology.

Furthermore, every major scientific advance was facilitated by technology; the microscope was crucial to the cell theory, cellular pathology, and the infectious theory of disease. Chemical analytical techniques were crucial for the development of biochemistry, cell biology, and pharmacology. Advances in understanding electricity and physics lead to the electrocardiogram, the electroencephalogram, and eventually to roentgenograms and more modern imaging.

The discovery of the structure of the DNA and the development of sequencing by Sanger and collaborators were essential steps leading to our modern molecular biology and genomics. However, only with the recent development of deep sequencing technology has molecular medicine been opened up to new possibilities for understanding health and disease. The progress in sequencing technologies is astounding. Ten years, thousands of scientists, and huge sums of money were required for the human genome project to create the first draft sequence, published in 2000. Today, several revolutionary new methods make genome sequencing a relatively inexpensive routine laboratory technique. All the major model organisms have been sequenced and routine sequencing for individual humans has arrived. Commercial laboratories offer the service for 
about $\$ 5,000$; in ten more years the costs may be $<\$ 1,000$. In 2012, what has been called "personalized medicine" is at its very beginning. Combinations of various "omics" evidences lead to the recent publication of a very detailed analysis of risk factors within a single patient [2].

In a further important step, an "evolutionary" approach to medicine studies the relationship between genomic data from humans with the ones of hominids and primates, in relation to the differences in symptoms of diseases across these different species [3-5]. Direct medical applications of identifying sequence variations associated with specific diseases receive the most attention; however, new sequencing technologies are also transforming evolutionary biology in ways that will make it far more important for medicine. We can now begin to answer questions about how life developed 3.5 billion years ago, when Homo sapiens diverged from African ancestors, when our species emerged from Africa, and even how much interbreeding occurred with Neanderthals [3]. Genomic data even allow inference about a previously unrecognized extinct line of hominids, the Denisova hominids. Darwin's revolutionary theory of evolution has been confirmed beyond any doubt, and is the foundation for a new and rapidly expanding field of precise science with profound potential benefits to human health.

\section{An unbroken line for 3.5 billion years}

The human body is a living archive of evolution, written in our genes, cells, and organs. The line is continuous to the beginning of life on this planet, so nature is inherently conservative. Sequences that are ancient parts of our genomic heritage tend to persist. Those important for survival and reproduction change less over the eons, so genes important for basic functions are generally "old" genes. The basic mechanisms that regulate cellular metabolism, cell division, and gene duplication are fundamentally the same as those occurring in unicellular organisms at the beginning of life on earth 3.5 billion years ago. Likewise, the molecules, cellular functions, organs, complex organization of muscles, bones, sensory organs, and nerves in vertebrates derive in an unbroken line from ancestors millions of years ago. Much of modern man's biology dates back to the origins of life; a complete understanding of this biology can only be appreciated with an evolutionary perspective [6].

\section{The origins of evolutionary medicine}

Attempts to understand why the body has apparent design "flaws", such as the appendix and the narrow birth canal, go back at least to William Paley in the early 1800s. However, Williams and Nesse were the first to call for systematic application of evolutionary biology to the problems of medicine in an article titled "The Dawn of Darwinian Medicine" $[7,8]$. Thanks to the efforts of many individuals, this field has grown rapidly. And thanks to the new advances in genomic and molecular medicine, this idea is about to grow faster yet, opening up new avenues to better understanding health and disease.

Darwinian (evolutionary) medicine is not a method of practice, nor is it in any way radical or controversial. It is merely the application of the basic science of evolutionary biology to medicine in the same way that genetic medicine applies the basic science of genetics. The idea augments the usual focus of medical research on the mechanisms of diseases by also asking why the body is constructed the way it is. Most medical research focuses on questions about mechanisms and how they differ in individuals with disease. These questions are "proximate". Evolutionary medicine focuses on how all individuals are alike in ways that leave them vulnerable to disease and how evolution could account for these vulnerabilities. These "evolutionary" or "ultimate" questions must also be answered to have a full understanding of the body and disease $[8,9]$.

Why are we the way we are? Why do diseases exist? Why are our bodies frail in certain respects? Why have certain organs, structures, mechanisms, and pathways been maintained throughout evolution, while others have not? [7] Such questions require evolutionary answers. One reason why our bodies have traits that make us vulnerable to disease is already familiar in medicine. There are some things natural selection just cannot do. Natural selection cannot prevent all mutations and it cannot continually "start freshover" to correct a poor design. This state-of-affairs is, however, only one of the reasons "why" we get sick. There are many other possible reasons why the body is not better $[7,9,10]$. One of the most important is that our bodies were not shaped to cope with the challenges that our bodies face in modern environments (Fig. 1).

\section{Ancient bodies in modern environments}

With their evolutionarily "old" biology, our bodies are unable to cope in the fundamentally new and fast-changing - mostly man-made artificial environments in which we live in now. The very existence of cities and machines is a dramatic example. No longer do we labor hard to harvest a scarce living in the Stone Age. No longer are we running away from big animals to avoid being eaten, or chasing smaller animals in order to provide food for our families. Modern urbanized society is now dependent on industrially manufactured food, ordered by smart phone from mega-stores, and delivered to our homes. We eat too much, and our preferred foods are salty, sweet, and full of fat. 


\section{Our Biology is old, Evolution is slow !}

The Mismatch (Gap)

results in

Diseases of Civilization

Obesity, Metabolic Syndrome...

Diabetes, Hypertension, Stroke...

Osteoporosis, Musculo - Skeletal System...

Mental Disorders, Depression...

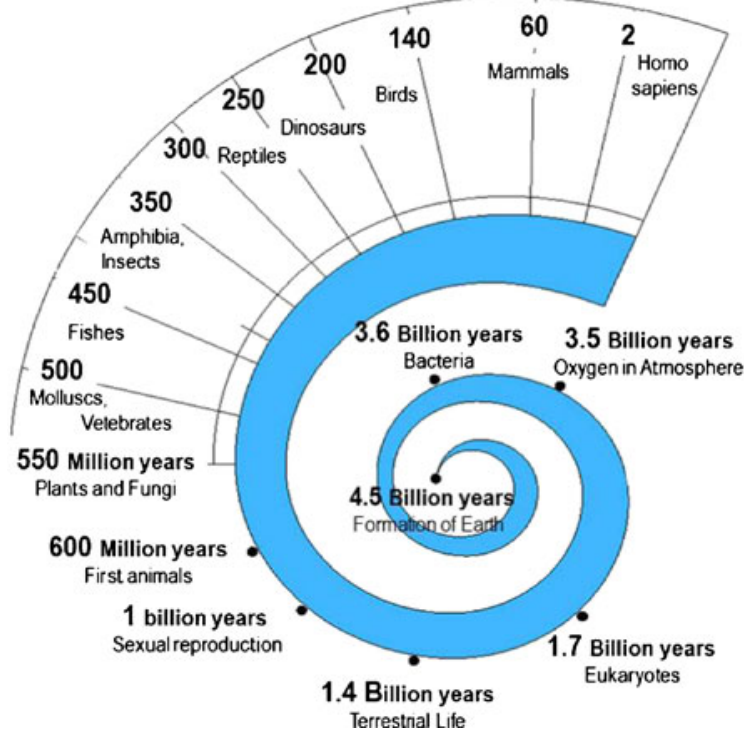

\section{Environment, Civilisation, Urbanisation is new, Changes are fast !}

Fig. 1 The basis for the development of diseases of civilization in modern times

Many of us make our living by sedentary pursuits, such as sitting in front of computers and moving knowledge electronically around the world. Energy is provided by fossil fuels transformed to electricity and transmitted along wires, instead of by calories from plants and meats fueling musculoskeletal activity. What are the consequences of living in this environment of ease and plenty? Obesity, diabetes, hypertension, cardiovascular disease, and certain cancers are a direct result. These so-called non-communicable diseases (NCDs) have become the predominant cause of human suffering and a major burden and challenge for society. International organizations such as the World Health Organization and the United Nations are doing their best to meet this challenge. Despite fast progress in medical research, the health trajectory of most of the earth's human populations is not improving; instead, it is worsening.

As scientists and as physicians, we must find new approaches. Improved understanding of evolutionary biology will provide new hypotheses and new lessons for NCDs, as well as how to better deal with infectious agents $[11,12]$. Early stimulation of the immune defense systems, as was the norm for our ancestors, and more intelligent use of antibiotics to avoid the evolution of drug resistant bacteria are just two practical applications of evolutionary concepts in medicine and public health $[13,14]$.
Diseases of civilization now account for more than $80 \%$ of the disease burden and costs in modern societies. They pose enormous new challenges. In newly industrializing countries, NCDs are becoming epidemic and in these countries obesity, diabetes, cardiovascular diseases, hypertension, musculoskeletal diseases, osteoporosis, and others are equally common as in more established industrial societies. The underlying cause of these "diseases of civilization" is modern lifestyles that are out of tune with our biological heritage.

For the well-off in our modern world, physical work is no longer necessary, and affordable motorized mobility makes even walking hardly necessary. Even small efforts are obviated by devices such as electric corkscrews and batterypowered pepper mills. Most people have achieved lives of comfort and ease of which our ancestors could only dream.

Meanwhile, it has become clear that perfectly comfortable lives tend to end prematurely from chronic diseases before their allotted time. Many millions of humans no longer challenge their bodies physically; this indolence leads to thinner, weaker muscles, whose abilities to burn carbohydrates and fat is decreased, as well as fragile bones, increased resistance to insulin, and increased atherosclerosis. From an evolutionary perspective, the bodies of physically inactive humans are in a highly exceptional state, one that self-destructs. 
Our modern civilization depends on close collaborations and exchanges of ideas among distant individuals, necessities in our fast-urbanizing globe. A century ago, $10 \%$ of the world population lived in cities. Today, $50 \%$ of the seven billion people on earth live in urban environment. In 20 years, $75 \%$ of the world population will live in cities, some of them with 50 million inhabitants and more [15].

Moving back to the countryside, as some romantic ecologists propose, is not a realistic solution for solving today's health problems. The great achievements that make humans unique and that explain our special path in the animal kingdom beyond biological evolution are our mostly peaceful coexistence in dynamic societies and our creative cooperation, based on a division of labor and the intellectual and cultural advantages of global cities. The challenge now is to use these intellectual and physical resources to create healthy societies.

\section{Public health}

Medicine improves the health of the public, but not nearly as much as public health. Acheson (1988) defined public health, as "the science and art of preventing disease, prolonging life, and promoting health through organized efforts of society." Public health considers the health effects of individuals interacting with environments, including nutrition, physical activity, climate, and social determinants of health in the broadest sense. Our modern understanding of evolution can be very useful for public health, and public health offers opportunities to understand many evolutionary phenomena, ranging from pathogen transmission and evolution to the constraints that leave us unable to cope effectively with many aspects of modern environments $[16,17]$.

For many diseases, we know why we get sick and know how to avoid illness. Far more effective and cheaper is to prevent a disease than to treat one. Prevention is the name of the game, and sanitation, vaccination, and education are effective preventive measures. Today's expensive medicines are not available to most of the seven billion people on the globe. New approaches are essential; evolutionary public health may help to provide them. Research scientists, practicing physicians, politicians, businessmen, and social leaders must find new ways to collaborate to ensure basic health rights. These rights include not only health care, but also strategies for creating societies that promote healthy living and lives. Health has the highest value for the individual and for society. The World Health Summit (www.worldhealthsummit.org) in Berlin chose an appropriate Leitmotiv in the Darwin year, 2009: "The Evolution of Medicine".

Public health will make faster progress in preventing disease as it makes more use of evolutionary approaches. Medicine will become more effective as it incorporates the principles of evolutionary biology. Recent advances in molecular biology poise both fields at the cusp of major advances. If they are developed on a foundation of evolutionary understanding, they will be far more effective at improving the health of individuals. Evolutionary Molecular Medicine holds great promise. The collection of manuscripts in this issue of the Journal of Molecular Medicine draws attention to these exciting developments. We hope they will encourage others to further advances.

Acknowledgments We thank David Fournier and Fred Luft for critical review of this manuscript.

\section{References}

1. Crespi BJ (2011) The emergence of human-evolutionary medical genomics. Evol Appl 4(2):292-314

2. Chen R, Mias GI, Li-Pook-Than J, Jiang L, Lam HY, Chen R, Miriami E, Karczewski KJ, Hariharan M, Dewey FE et al (2012) Personal omics profiling reveals dynamic molecular and medical phenotypes. Cell 148(6):1293-1307

3. Enard W (2012) Functional primate genomics-leveraging the medical potential. J Mol Med. doi:10.1007/s00109-012-0901-4

4. Varki A (2012) Nothing in medicine makes sense, except in the light of evolution. J Mol Med. doi:10.1007/s00109-012-0900-5

5. McConkey EH, Varki A (2005) Genomics. Thoughts on the future of great ape research. Science 309(5740):1499-1501

6. Fournier D, Luft FC, Bader M, Ganten D, Andrade-Navarro MA (2012) Emergence and evolution of the renin-angiotensinaldosterone system. J Mol Med. doi:10.1007/s00109-012-0894-Z

7. Nesse RM, Williams GC (1994) Why we get sick - the new science of Darwinian medicine. Times Books, New York, NY

8. Williams GC, Nesse RM (1991) The dawn of Darwinian medicine. Q Rev Biol 66(1):1-22

9. Nesse R, Omenn G, Ganten D, Gregory TR (2012) What modern evolutionary theory offers to medical genetics. J Mol Med. doi:10.1007/s00109-012-0889-9

10. Straub RH (2012) Evolutionary medicine and chronic inflammatory state - known and new concepts in pathophysiology. J Mol Med. doi:10.1007/s00109-012-0861-8

11. Ewald P, Ewald HS (2012) Infection, mutation, and cancer evolution. J Mol Med. doi:10.1007/s00109-012-0891-2

12. Hill AL, Rosenbloom DIS, Nowak MA (2012) Evolutionary dynamics of HIV at multiple spatial and temporal scales. J Mol Med. doi:10.1007/s00109-012-0892-1

13. Barreiro LB, Quintana-Murci L (2010) From evolutionary genetics to human immunology: how selection shapes host defence genes. Nat Rev Genet 11(1):17-30

14. Schmid-Hempel P (2011) Evolutionary parasitology: the integrated study of infections, immunology, ecology, and genetics. Oxford University Press, USA

15. LSE Cities, Deutsche Bank's Alfred Herrhausen Society, University of Hong Kong (2011) Cities, Health and Well-Being. Hong Kong Urban Age Conference, 16-17 November 2011

16. Nesse RM, Stearns SC (2008) The great opportunity: evolutionary applications to medicine and public health. Evol Appl 1(1):28-48

17. Omenn GS (2010) Evolution and public health. Proc Natl Acad Sci 107(S1):1702-1709 